Received Date : 09-Jan-2016

Revised Date : 08-Aug-2016

Accepted Date : 07-Oct-2016

Article type : Original Article

\title{
Game of Hospitals
}

\section{Ruvini Vithanage, Benita Knox and Anna Ryan}

Department of Medical Education, University of Melbourne, Melbourne, Victoria, Australia

\begin{abstract}
Background: Systems of healthcare is a key learning area in medical curricula(1). An understanding of the healthcare system in regard to reducing medical errors, improving efficiency in the provision of care, and cost containment is recognised as being difficult to teach.
\end{abstract}

Context: A game-based session was designed and executed as part of a medical student conference. This session incorporated numerous aspects of systems of healthcare including team-work, efficient and equitable allocation of resources, safety, quality, medical errors, structure of healthcare systems and political influences in the delivery of healthcare.

Innovation: Game of Hospitals employs experiential learning, enhanced by role-play and competition. Students take on roles as hospital administrators and doctors to negotiate complex clinical and administrative problems. The scenarios explore themes and highlight patient outcomes and the finite nature of resources. Student experiences were observed and questionnaire evaluations attempted to explored student perceptions. Implications: Game of Hospitals appears to be a popular learning activity. Observations during the game demonstrated active involvement of participants, and questionnaire evaluation revealed this to be a favourite session at the student conference. This paper

This is the author manuscript accepted for publication and has undergone full peer review but has not been through the copyediting, typesetting, pagination and proofreading process, which may lead to differences between this version and the Version of Record. Please cite this article as doi: $10.1111 /$ tct.12615

This article is protected by copyright. All rights reserved 
presents a detailed explanation of the set-up and rules for the game, in the hope that others can adopt and modify the game to suit their local context.

\section{Introduction}

Knowledge of systems of healthcare, also termed systems based practice (SBP) is recognised as a key component of professional knowledge and behaviour, with particular relevance in reduction of medical error, improved efficiency and containment of costs(1). The 1999 report 'To Err is Human'(2) highlighted the need for more explicit training in the area in the United States. This work arguably led to a much more explicit focus on the concept with the inclusion of SBP into the Accreditation Council for Graduate Medical Education (ACGME) guidelines(3) and subsequently into University medical programs(4). Whilst it is universally accepted as important, it is also well recognised that SBP can be difficult to teach. Implementation within educational settings has proved challenging with content being perceived as uninspiring and unengaging for students(1, 5). Documented successful approaches have been largely experiential in nature(1,6). Experiential learning, as popularised by $\mathrm{Kolb}(7)$ involves reflective observation, abstract conceptualisation, active experimentation and concrete experience, and can prove useful in teaching content where engagement is an issue. In particular, game-play and scenariobased simulation has been identified as an effective pedagogical method for topics known to suffer from lack of student engagement(6).

\section{Context}

The University of Melbourne Doctor of Medicine program (MD) is a four-year graduateentry program, comprised of a non-clinical first year and three clinical years. All 1400 students come together for a four-day annual student-organised conference. Students of all year levels volunteer to work in small teams to design and lead conference sessions that are based on graduate attributes. Game of Hospitals $(\mathrm{GoH})$ was first developed as a conference session under the theme "Systems of Healthcare". This theme incorporates a number of competencies including teamwork, an understanding of quality and safety frameworks, and the national healthcare system.

\section{Method}

The team of students organising the $\mathrm{GoH}$ session brainstormed possible approaches to exploring SBP. To challenge the common perception of SBP being uninteresting, a game 
model was chosen with the aim of making it more playful and engaging. It became apparent that the game could be refined to draw on the principles of experiential learning as this recognises the role of experience in shifting thinking. It was considered that having students "experience" the role of doctor or administrator could have learning benefits. Furthermore, the learning stages of reflective observation, abstract conceptualisation and active experimentation could be an effective foundation for the structure of the game.

The team voted on topics that would become the game's scenarios. Team-work, efficient and equitable allocation of resources, quality and medical errors were selected. Scenarios were developed through brainstorming, research, group discussion and consultation with clinicians and academics (Table1). The drafting followed an iterative process, with continual review by the team and senior medical educator.

A pilot study was run in 2013, prior to the first conference session. Twelve volunteer medical students from all year levels assessed the efficacy of the game and their feedback was reviewed and incorporated as appropriate.

\section{INSERT TABLE 1 HERE}

GoH was launched at the 2013 medical student conference as a single 90 minute conference session, open to students from all year levels. In 2014 it was run twice involving 240 students (approximately one sixth of students) with approximately 60 from each year level. With minor adaptations, it was delivered as a teaching session within the formal curriculum for first year medical students in 2013 and for medical students from different universities at the Future of General Practice Conference 2015. Three different facilitators delivered the session on five different occasions. After each delivery a similar review and improvement process was implemented.

Figure 1 provides an infographic representation of all key aspects of Game of Hospitals. Here the "Administrators" and "Doctors" are roles played by participants and the outcome of each scenario is documented in "Logbooks" and "Manuals" supply additional information for the players pertaining to each scenario.

\section{INSERT FIGURE 1 HERE}


A university survey captured overall student conference experience and asked students to agree or disagree on a five-point Likert scale as to whether each session increased their understanding in a specific domain. A more specific online survey targeting knowledge of SBP in general and the GoH session was developed and distributed via the centralised student portal following the 2014 conference. As there were no relevant validated surveys available in the literature,, a twelve-item survey was adapted from these graduate attribute themes. Students were asked to rate their perceived understanding of the session's learning objectives on a five-point Likert scale. The University Human Ethics Research Committee provided ethics approval.

\section{Results}

$\mathrm{GoH}$ was observed to generate playful and enthusiastic debate amongst participants. $\mathrm{GoH}$ was designed to function as a transferrable learning tool and was observed to behave as such, being used in a number of settings, with different facilitators, and involving participants of differing backgrounds. In all sessions lively discussions between "doctors" and "administrators" were heard throughout as they battled with their competing priorities (a combination of Kolb's active experimentation and concrete experience)(7). In the infection control scenario, students were observed to grapple with their pre-existing conceptions regarding hand hygiene and the comparative effectiveness of other options (abstract conceptualisation). Facilitators assisted students to reflect from various perspectives and subsequently consider the systemic impacts (reflective observation). At the UoM MD Student conference in 2013, 43 of GoH participants responded (36\%). $90 \%$ of respondents agreed or strongly agreed that $\mathrm{GoH}$ strongly increased their understanding of SBP. In 2014 a total of 61 participants responded (25\%). 74\% agreed or strongly agreed that GoH strongly increased their understanding of SBP.

All conference attendees were requested to complete the more specific SBP survey and 215 responded ( $15 \%$ response rate). 54 of the respondents $(25 \%)$ had attended $\mathrm{GoH}$ in 2013 and/or 2014. The survey demonstrated no difference in the perceived understanding of SBP between those who had attended GoH and those who had not, but that latter year students were more confident in their understanding of a. efficient allocation and b. equitable allocation of resources in SBP. No free-text comments were provided by respondents.

\section{Discussion}

This article is protected by copyright. All rights reserved 
$\mathrm{GoH}$ aims to engage participants in experiential learning through discussions around scenarios and their solutions. The basis of $\mathrm{GoH}$ learning objectives, the graduate attributes, are shared by many medical schools and subsequently this could be a useful methodology for teaching these concepts at other institutions. Over four rounds, students took on the role of administrator or doctor to tackle complex scenarios. They were prompted to engage in active experimentation and reflective observation, exploring dynamics, relationships and implications in the healthcare system in a safe and controlled environment.

The use of $\mathrm{GoH}$ with different student cohorts and learning environments highlights its potential adaptability. GoH was very popular at the student conference; in the absence of qualitative data, we have postulated the interactive gameplay model was central to its success. There is limited evidence regarding the most effective timing for delivering material on SBP (6), however GoH has been played by students from all year levels of our program suggesting it could be incorporated flexibly into medical courses. We are currently working with another university to use $\mathrm{GoH}$ to teach key concepts in public health, and have made some variations to the game design such as including community members as stakeholders. The GoH model could potentially be adapted to teach other traditionally 'dry' topics such as epidemiology - tables could function as countries, each with their own budget and epidemiological information to solve global health problems.

Interestingly, there was a trend where students who attended GoH were more likely to perceive their understanding of SBP as worse than those who did not attend, which may be attributed to increased insight into the complexity of issues of SBP.

There were a number of limitations to our research. The lack of validated questionnaire exploring medical students' knowledge of SBP, low response rate and lack of free-text responses have limited possible analysis and conclusions. We were also only able to assess students' perceived understanding. Measuring competency in SBP is difficult using traditional measuring tools (8). Studies to date have also employed self-reporting of competence in this domain $(1,6)$. While a longitudinal evaluation of interventional outcomes would be ideal, numerous barriers to evaluating outcomes in teaching SBP have been identified in the literature and include, time, cost and logistics and the breadth of the subject matter(9).

As learning in this domain has proven difficult to quantify, further research is required regarding teaching of SBP and alternative means to analyse this learning. In future

This article is protected by copyright. All rights reserved 
iterations we plan to develop and validate a questionnaire, consider interview and focus groups as a method of obtaining qualitative data, and obtain documentation of the discussion during the game through videorecording.

SBP has been identified as a learning need by medical students prior to them engaging with the system itself as a practitioner(10). GoH is popular among medical students. We believe that game-play has the potential for engaging students in SBP. This paper provides a detailed outline of $\mathrm{GoH}$ so that this innovative experiential teaching tool can be adopted within other health care education settings.

\section{References}

1. Colbert CY, Ogden PE, Lowe D, Moffitt MJ. Students learn systems-based care and facilitate system change as stakeholders in a free clinic experience. Advs Health Sci Educ. 2010;15(4):533-45.

2. Kohn L, Corrigan J, Donaldson M. To Err is Human. Washington DC: Institute of Medicine, 1999.

3. Swing SR. The acgme outcome project: Retrospective and prospective. Med Teach. 2007;29(7):648-54.

4. Issenberg SB, Chung HS, Devine LA. Patient safety training simulations based on competency criteria of the accreditation council for graduate medical education. Mt Sinai $J$ Med. 2011;78(6):842-53.

5. Boltri JM, Vogel RL, Tindall WN, Tedders SH. Improving medical students' knowledge of systems-based practice. Manag Care Q. 2002;10(1):29-32.

6. Sheu L, O'Brien B, O'Sullivan PS, Kwong A, Lai CJ. Systems-based practice learning opportunities in student-run clinics: A qualitative analysis of student experiences. Acad Med. 2013;88(6):831-6.

7. Kolb D. Experiential learning: Experience as the source of learning and development. Engewood Cliffs, NJ: Prentice-Hill; 1984.

8. Colbert CY, Ogden PE, Ownby AR, Bowe C. Systems-based practice in graduate medical education: Systems thinking as the missing foundational construct. Teach Learn Med. 2011;23(2):179-85.

9. Delphin E, Davidson M. Teaching and evaluating group competency in systemsbased practice in anesthesiology. Anesth Analg. 2008;106(6):1837-43. 
10. Association of American Medical Colleges. Medical School Graduation Questionnaire: 2011 All Schools Summary Report. https:// www.aamc.org/data/gq/allschoolsreports/.

Corresponding author's contact details: Ruvini Vithanage, Department of Medical Education, Melbourne Medical School Medical Building (181), Level 2 West, The University of Melbourne, Melbourne, Victoria, 3010, Australia. E-mail: ruvini.vithanage@gmail.com

Funding: None.

Competing interests: None.

Acknowledgements: The authors would like to thank and gratefully acknowledge the guidance, encouragement and contributions of Professor Geoff McColl from the University of Melbourne, Professor Stephen Trumble from the University of Melbourne and the University of Melbourne MD Student Conference organising teams of 2013 and 2014. The authors are also grateful for Tim Leurs from Zero21 for his expertise and contribution regarding the infographic.

Ethical approval: Ethical approval was sought from the Human Ethics Advisory Group at the University of Melbourne, Department of Medical Education. Ethical approval was granted under Ethics approval ID: 1442368.

\section{LEGENDS}

Table 1: Themes and scenarios used in the 2014 student conference. (A full list of scenarios used can be found in Appendix II)

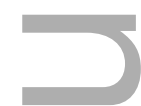

Figure 1: The Game of Hospitals (Legend: S1 - Scenario 1, S2 - Scenario 2, S3 Scenario 3, S4 - Scenario 4, S5 - Scenario 5) (A text version of the infographic can be found in Appendix I) 


\section{SUPPORTING INFORMATION}

Additional Supporting Information may be found in the online version of this article:

Appendix 1. Instructions for "Game of Hospitals".

Appendix 2. "Game of Hospitals".

-
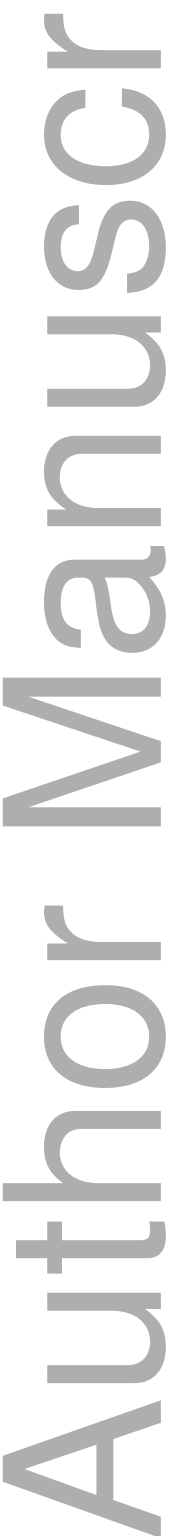

This article is protected by copyright. All rights reserved 


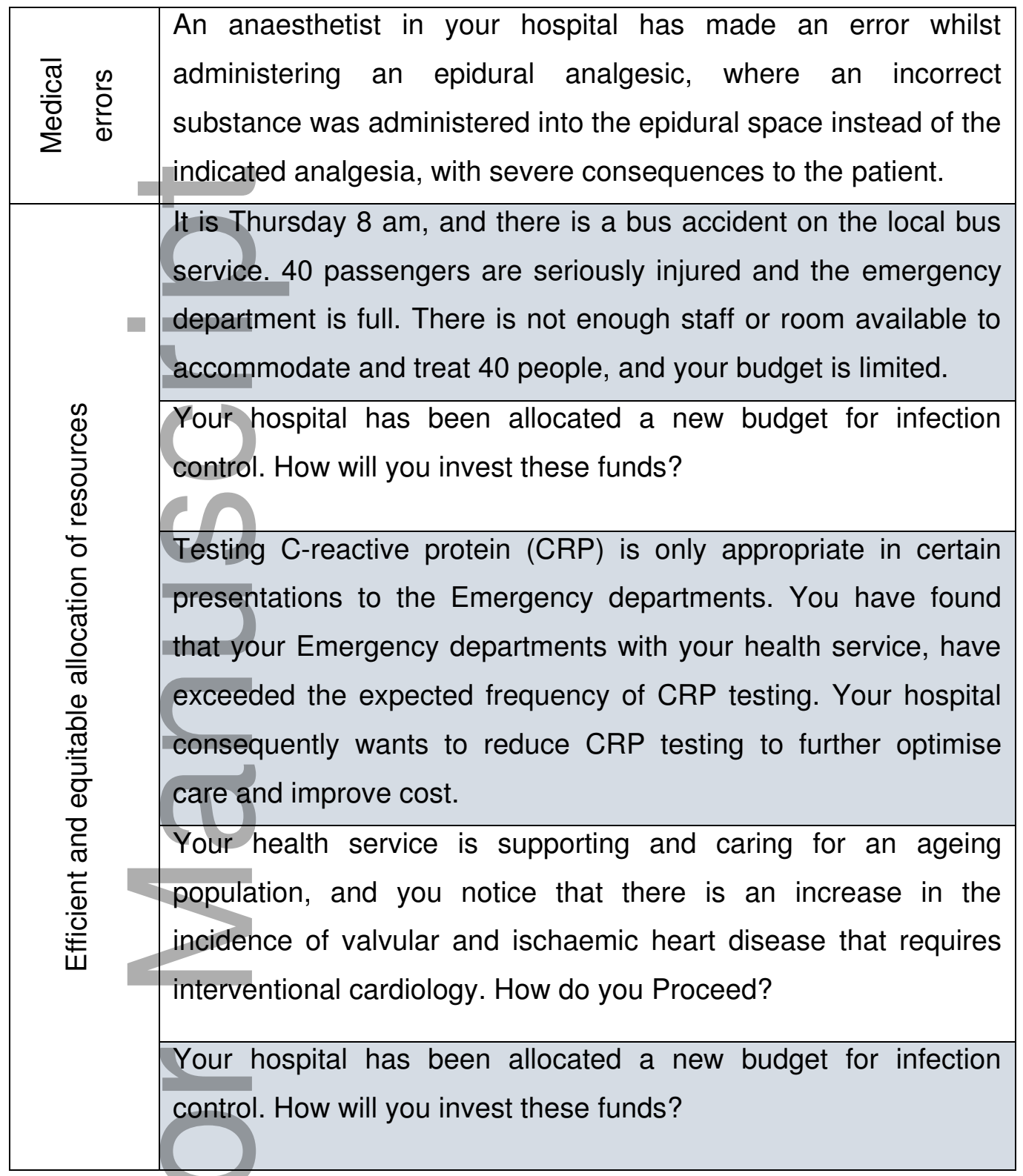

Table 1: Themes and scenarios used in the 2014 student conference. (A full list of scenarios used can be found in Appendix II)

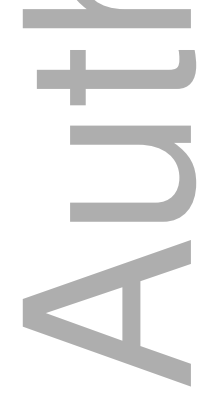

This article is protected by copyright. All rights reserved 


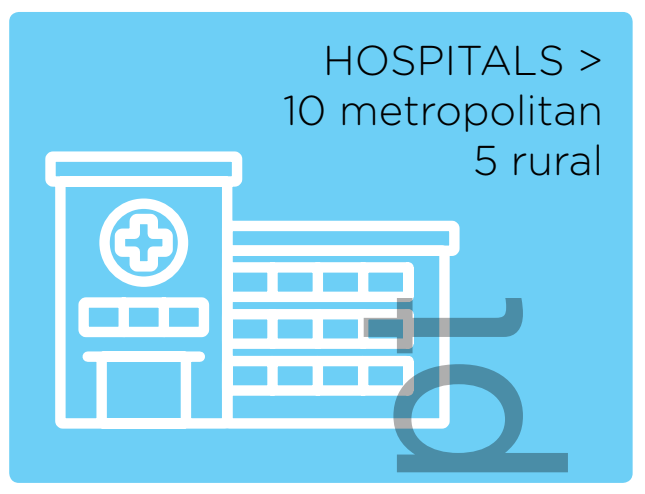

-

\section{FACILITATORS \\ TO THE GAME >}

HEAD FACILITATOR > Orchestrates the game-play, and leads the inter-hospital discussion

CO-FACILITATORS > 4 circulating co-facilitators to further intrahospital discussion, collect coins and distribute gold stars

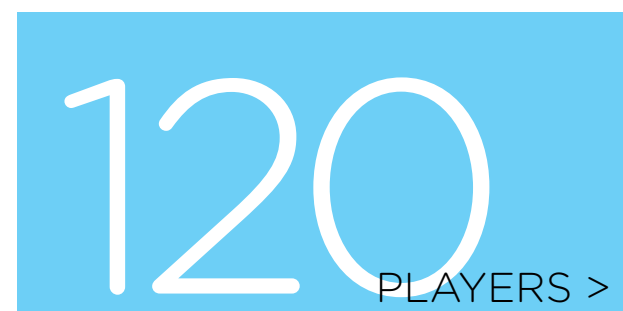

8 players around each table, with each table representing a hospital

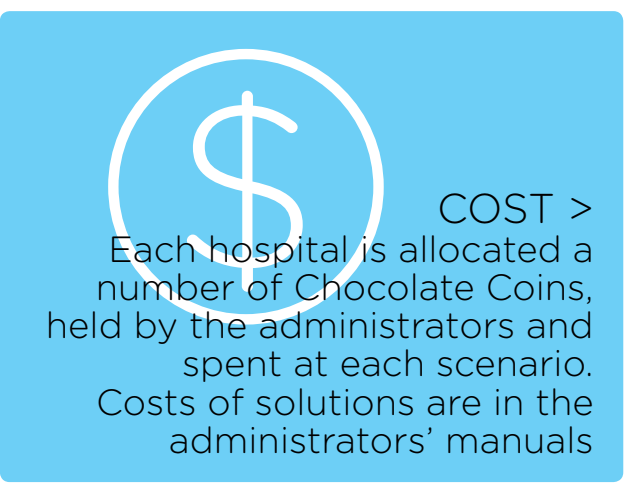

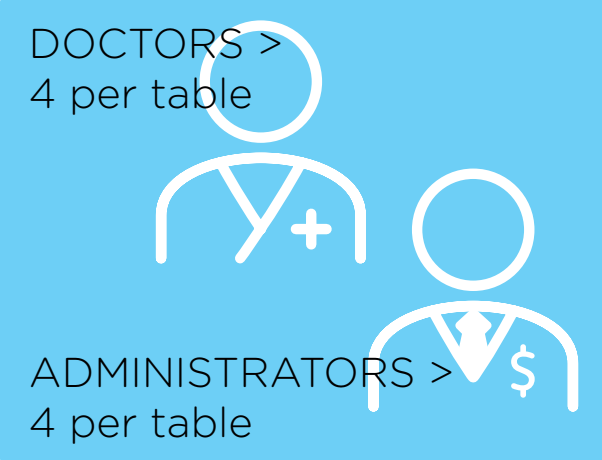

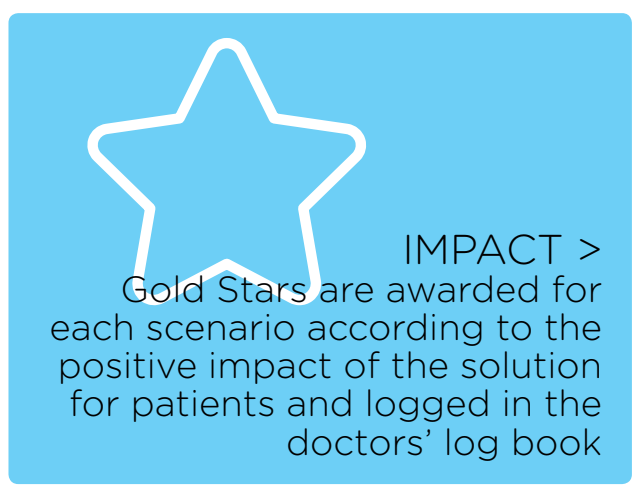

\section{GAME SEQ
90 minutes}

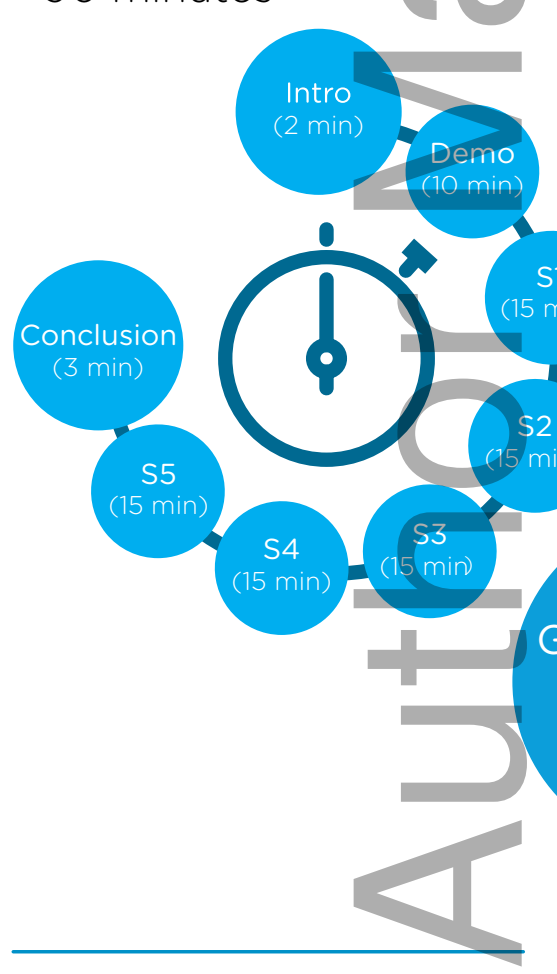

COMPLETION OF

THE GAME >

Gold Stars and

Chocolate Coins

tallied. The hospital

with the most Gold

Stars wins; in case of a draw, Chbhis|artedicle is protected by copyright. All rights reserved
GAME PLAY FOR EACH SCENARIO > 15 minutes
( 4 min)

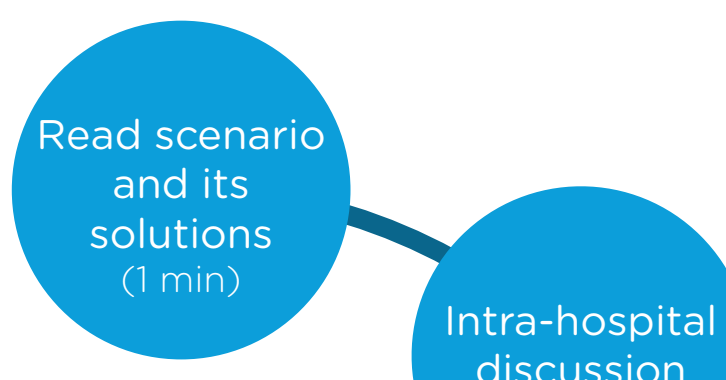

discussion

(5 min)

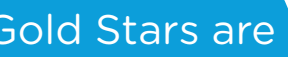
distributed

(1 min)

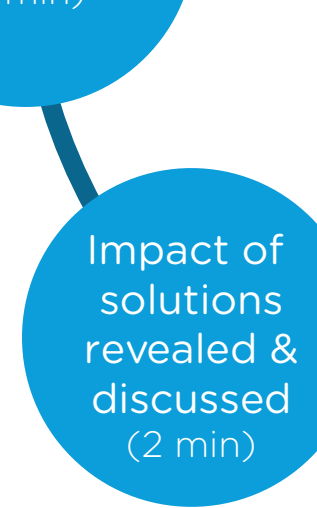

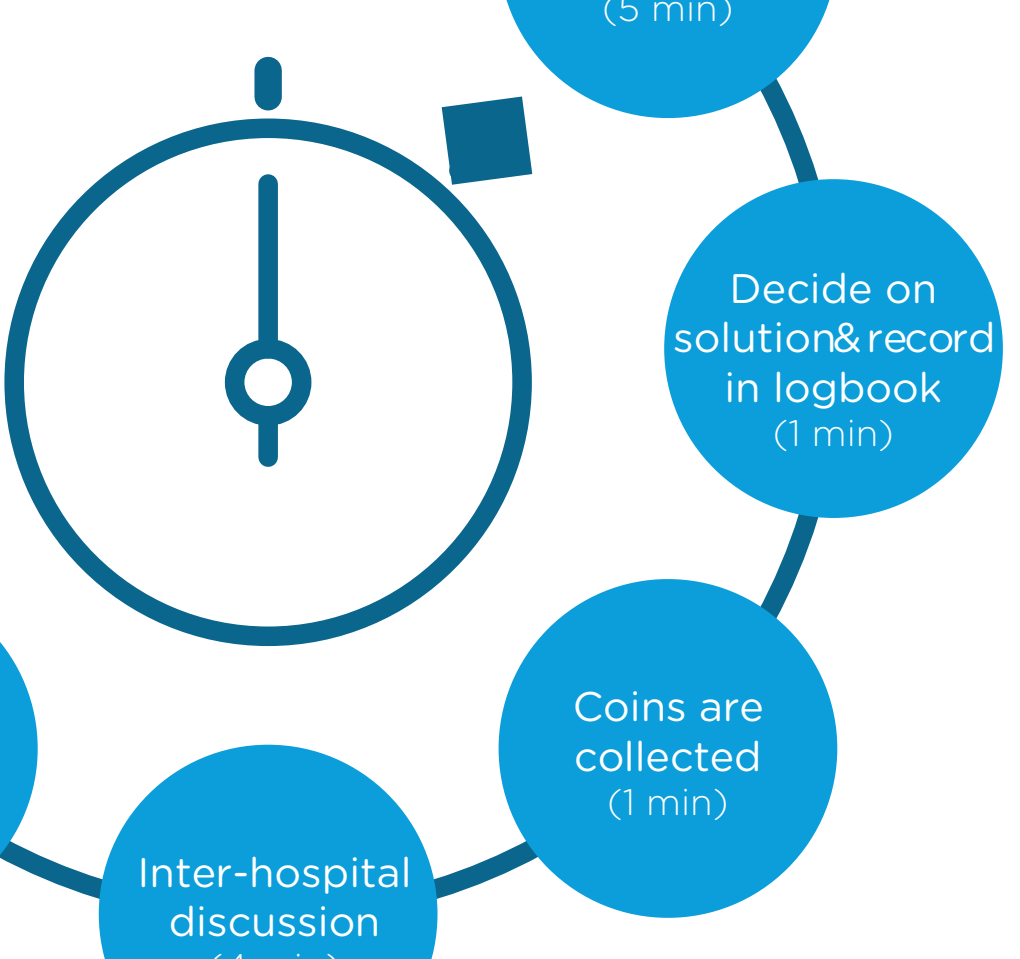

discussion Coins are counted. 


\section{University Library}

\section{- M M I N E R VA A gateway to Melbourne's research publications}

Minerva Access is the Institutional Repository of The University of Melbourne

Author/s:

Vithanage, R;Knox, B;Ryan, A

Title:

Game of Hospitals

Date:

2017-08-01

Citation:

Vithanage, R., Knox, B. \& Ryan, A. (2017). Game of Hospitals. CLINICAL TEACHER, 14 (4), pp.279-283. https://doi.org/10.1111/tct.12615.

Persistent Link:

http://hdl.handle.net/11343/292642 